held until his retirement in 1984. He was very happy in Oxford, enjoying dining rights at Wadham College and becoming a Fellow of Green College.

A number of honours were granted him in appreciation of his contribution to psychiatry and literature. He was elected Emeritus Fellow of Green College (1984)
Fellow of the Royal Society of Literature (1990) and Honorary FRCPsych (1993). The generosity of spirit, so apparent in his writing, was no less evident in his personality and was freely expressed in the warm support and encouragement he gave to younger psychiatrists, psychotherapists and writers, as well as to the patients from all walks of life who came to consult him. He died on 17 March 2001, aged 80. Storr was twice married, first to Catherine Cole, the writer with whom he had three daughters before a divorce in 1970. They survive him, as does his second wife, Catherine Peters. Anthony Stevens

\title{
reviews
}

\section{Introduction to Medical Law}

By Peter Marquand. Oxford: Butterworth-Heinemann. 2000 125 pp. $f 15.99$ (pb.)

ISBN: 0-7506-4239-4

While I have been reading this book over the last few weeks the media has been full of cases in which many aspects of medical law have been aired, including the court actions surrounding the separation of conjoined twins born in Manchester. The book helped me sort out some of the journalistic flannel and understand what the real legal issues are.

Near the beginning of the book the authors look at the issues of capacity and consent. Capacity is one of the most complex and frequently misunderstood concepts in medical treatment and the simple explanation offered goes a long way to clarifying it. Most doctors only need a detailed understanding of the concept of capacity when a difficult clinical situation arises and the book would be a useful reference to refresh anyone's memory when needed.

The remaining chapters cover many important aspects of law. Only the chapter on risk management seems slightly out of place, as it is not clear why this subject, which seems to be more about good clinical practice than the law is included. As a psychiatrist, the chapte on the Mental Health Act appears rather simplistic and does not go into the subtleties of the Act, which are part of day-to-day psychiatric practice. Similarly, the chapter on drugs and prescribing does not go into the detail that a substance misuse psychiatrist would find helpful. However, the chapters on subjects I do not know well, such as wills, abortion and transplant law, I found incredibly interesting.

This book, like any other introductory text, only summarises the issues it covers.
There is no discussion of issues such as the reforms of the Mental Health Act and the General Medical Council. The book finishes appropriately with a reassuring practical chapter on defending a criminal negligence claim and another that offers guidance on report writing for experts in civil cases.

This book is exactly what it says - an introduction to medical law. It is written for all doctors and as such has little detail on issues relevant to psychiatrists. It will, though, be a very useful reference text on the more general issue of the law as applied to medicine and invaluable to trainees in any branch of medicine. I will treasure my copy carefully!

Emily Finch Consultant in Substance Misuse South London and Maudsley NHS Trust

\section{Pull yourself together! A survey of the stigma and discrimination faced by people who experience mental distress}

The Mental Health Foundation. 2000. 27 pp. $£ 10.00$ (pb). ISBN: 0-901944-87-4

What is the best way to influence mental health policy? One approach used by the Mental Health Foundation, the UK's largest mental health charity, is to publish reports that aim to educate and inform on mental health issues. Concern that the stigmatisation of mental illness prevents individuals acknowledging their difficulties and seeking appropriate help was the impetus behind this survey.

This reviewer's problem was whether to read this report as scientific literature, or as an account of individuals' experiences. The postal survey included health professionals and service users on the charity's mailing list. Supporters of a campaigning body are more likely to report their negative experiences and this raises the question of what population those surveyed represent. In addition, a response rate of only $13 \%$ calls into doubt the validity of the study.

Of the replies received, $70 \%$ reported discrimination in various settings, and respondents were asked to describe their experiences. Stigmatising views encountered included the fear that mental illness is contagious and that it represents a character flaw. Several people perceived that their mental distress had been dismissed by doctors and that comorbid physical problems were taken less seriously. The difficulties in finding appropriate health care and applying for work, or the experiences of being shunned by friends and families, are sobering reading.

This is where the report is more successful, as narrative rather than as quantitative research. As such, the study is a useful resource for those planning qualitative research into stigma and mental health. In addition it provides suggestions on how stigma can be chalenged. These include the proposal that interested organisations combine in an anti-discrimination campaign.

Disappointingly, the authors seem to be unaware of the College's Changing Minds Campaign, which suggests that communication between the College, charities and self-help groups must be improved if we are to get the message across. Perhaps we need to combine the emotive accounts contained in this survey with the rigour of scientific research.

The instruction of the report's title should be addressed at the mental health charities and at the College. When we pull 'ourselves' together, our influence on mental health policy will be greatly enhanced.

Jim Bolton Lecturer, Department of Psychiatry, St George's Hospital Medical School, CranmerTerrace, ondon SW17 ORE

\section{miscellany}

\section{Sydney job swap}

Dr C. Wijeratne, Consultant Old Age Psychiatrist working in Sydney teaching hospital, wishes to swap job and home with a similar colleague working in England, commencing after August 2002, for about 2 years. Those interested can contact Dr Wijeratne at the following address: Dr C. Wijeratne, 1
Edna St, Willoughby, NSW 2068, Australia. Alternatively, e-mails can be sent to: wijeratnec@sesahs.nsw.gov.au. 